\title{
A representação do movimento dos posseiros de Cotaxé na obra literária de Adilson Vilaça
}

\author{
Victor Augusto Lage Pena ${ }^{1}$
}

Resumo: Este artigo discute a representação criada na obra literária de Adilson Vilaça sobre o Movimento Udelinista, organização dos posseiros do noroeste do Espírito Santo em luta por acesso e permanência nas terras utilizadas para subsistência. Essa organização foi liderada por Udelino Alves de Matos, inicio-se na primeira metade da década de 1940, tendo o seu fím no ano de 1953, após repressão policial. O movimento é constantemente comparado com Canudos, sendo compreendido como um movimento messiânico. Objetiva-se nesse artigo entender como as obras literárias de Adilson Vilaça contribuíram para a construção e perpetuação desta representação. Comparamos, neste artigo, a interpretação das obras literárias com documentos primários e a memória dos moradores da região, principalmente da vila de Cotaxé, onde foi o foco do movimento.

Palavras-chave: Representação; Literatura; Memória; Movimento Udelinista.

Abstract: This article discusses the representation created in the literary work of Adilson Vilaça on the Udelinista Movement, organized by squatters in the northwestern state of Espírito Santo in struggle for access and permanence in the lands used for subsistence. This organization was led by Udelino Alves de Matos, which began in the first half of the 1940s, ending in 1953 after police repression. The movement is constantly compared to Canudos, being understood as a messianic movement. This article aims to understand how the literary works of Adilson Vilaça contributed to the construction and perpetuation of this representation. In this article, we compare the interpretation of literary works with primary documents and the memory of the residents of the region, especially the town of Cotaxé, where it was the focus of the movement.

Keywords: Representation; Literature; Memory; Udelinista movement.

${ }^{1}$ Graduado em História pela Universidade Federal do Espírito Santo e Mestre em História pela Universidade Federal de Ouro Preto. E-mail: victoraugustopena@hotmail.com.

Revista Vernáculo n. ${ }^{\circ} 41$ - primeiro semestre /2018

ISSN 2317-4021 
Neste artigo apresenta-se a representação do movimento organizado pelos posseiros de Cotaxé, denominado Movimento Udelinista, e do seu líder, Udelino Alves de Matos, na obra literária Cotaxé, além do trabalho historiográfico intitulado Cotaxé: a reinvenção de Canudos, ambos de Adilson Vilaça. Busca-se compreender, não só a representação, mas a sua origem e qual era o contexto de sua criação.

O Movimento Udelinista consiste em um movimento agrário, ocorrido em uma região de litígio entre os Estados do Espírito Santo e Minas Gerais, no final da década de 1940 e início da década de 1950. Ele objetivava garantir a permanência dos posseiros na região, e acesso à terra àqueles que ainda não a possuíam, queriam assim impedir o surgimento de grandes fazendas, mantendo a região como lugar de pequenas propriedades. Porém, surgem na região fazendeiros que teoricamente compraram as terras, nem sempre com documentações comprovadas. Por se tratar de uma região litigiosa, ora a documentação era do Espírito Santo, ora de Minas Gerais.

O conflito entre posseiros e grileiros ocorreu em meio a um litígio fronteiriço entre Minas Gerais e Espírito Santo. “Em 1963, o governo de Minas Gerais voltou a sugerir negociação para um acordo. Desta vez houve e foi aprovado. [...]. Já não há dúvidas nas divisas [do Espírito Santo] com Minas Gerais." ${ }^{2}$. Assim foi definida a fronteira entre mineiros e capixabas. Hoje, o distrito de Cotaxé pertence ao município

${ }^{2}$ MORAES, Cícero. As questões de limites que o Espírito Santo sustentou. Vitória: Real Gráfica, 1971. P. 46, 47.

Revista Vernáculo n. ${ }^{\circ} 41$ - primeiro semestre $/ 2018$

ISSN 2317-4021 
de Ecoporanga, território atual do Espírito Santo. Com a divisão atual, o Espirito Santo ficou com os territórios que hoje são Ecoporanga, Mantenópolis, Barra de São Francisco, Água Doce do Norte e Mucurici. Já Minas Gerais ficou com o território que hoje é município de Mantena e parte de Carlos Chagas.

Houve algumas trocas de tiros entre os militares de Minas Gerais e do Espírito Santo durante esse litígio territorial, porém, o maior gerador de violência na região era a lutas por propriedades de terra traçadas por posseiros e grandes fazendeiros. Havia dois conflitos concomitantes na região, e sem um estado definido havia pouca interferência estatal, o que gerava uma violência descontrolada na região. Esses movimentos também geraram na população um recorrente sentimento de medo no Vale dos Aimorés ${ }^{3}$.

O Movimento Udelinista ocorre no período do Governo de Getúlio Vargas, que, por ter uma imagem popular de "pai dos pobres" acabava criando, no imaginário popular, a ideia de que ajudaria os pequenos agricultores, posseiros e demais trabalhadores do campo. Udelino Alves de Matos, líder dos posseiros de Cotaxé, chega a enviar cartas para o presidente, além de ir duas vezes ao Rio de Janeiro, pessoalmente, para falar com o chefe do executivo.

Essas cartas de trabalhadores do campo a Vargas eram tão comuns que até foram reunidas em um trabalho historiográfico de

${ }^{3}$ Nome dado a região de litígio entre os dois estados. Faz menção aos índios que habitavam aquelas terras em períodos anteriores.

Revista Vernáculo n. ${ }^{\circ} 41$ - primeiro semestre /2018

ISSN 2317-4021 
Vanderlei Vazelesk Ribeiro, intitulado Cartas ao Presidente Vargas: outra forma de luta pela terra. Em seu trabalho ele afirma que:

Pode-se perceber não apenas que o regime Vargas buscou atuar no meio agrário, mas que os trabalhadores, inclusive os do campo, também buscaram aproveitar o discurso oficial para atingir objetivos como o acesso à terra, a resolução de conflitos agrários ou, mais simplesmente, meios para trabalhar, como enxadas ou recursos financeiros. ${ }^{4}$

Percebemos então, que o Movimento Udelinista, apesar de não dialogar diretamente com outros movimentos, estava em um caminho político, de resistência, comum a sua época. E, assim como a maioria dos movimentos do campo, foi respondido com repressão.

Em fevereiro de 1953, a Polícia Militar do Espírito Santo fizera um cerco policial na Casa de Tábua, local onde se reunião os udelinistas. Muitos posseiros morreram nessa ação. Udelino Alves de Matos consegue fugir, porém nunca mais foi visto na região de Cotaxé. Assim acaba a primeira fase do movimento dos posseiros de Cotaxé, denominado, Movimento Udelinista. Vale ressaltar que os posseiros se reorganizam em momentos posteriores, já com a ajuda do Partido Comunista do Brasil.

Surge, a partir desses conflitos, uma série de representações sobre o movimento. Portanto, os objetos de análise deste artigo, além do

${ }^{4}$ RIBEIRO, Vanderlei Vazelesk. Cartas ao Presidente Vargas: outra forma de luta pela terra. In.: MOTTA, Márcia; ZARTH, Paulo (orgs.) Formas de resistência camponesa: visibilidade e diversidade de conflitos ao longo da história, vol. I: concepções de justiça e resistência nos Brasis. São Paulo: Editora UNESP; Brasília: Ministério do Desenvolvimento Agrário, NEAD, 2008. p. 54.

Revista Vernáculo n. ${ }^{\circ} 41$ - primeiro semestre $/ 2018$

ISSN 2317-4021 
Movimento Udelinista em si, é a sua representação presente nas obras de Adilson Vilaça. Acredita-se que a obra literária, por ser pioneira, se torna a representação dominante, atingindo o imaginário local.

Ao trabalharmos com o conceito de "representação", o utilizamos a luz das ideias de Roger Chartier. E mais do que compreender as representações, nos interessa compreender as "lutas de representação", pois:

As lutas de representações têm tanta importância como as lutas econômicas para compreender os mecanismos pelos quais um grupo impõe, ou tenta impor, a sua concepção do mundo social, os valores que são os seus, e o seu domínio. ${ }^{5}$

Devemos compreender, que nos jogos de representação, sempre haverá lados opostos que disputam o discurso sobre um passado. A memória que será construída tem valor simbólico, pois justificará, ou não, ações do passado, justificando, ou não, comportamentos do presente. Há, portanto, interesse de grupos nesses discursos. Completando as ideias de Chartier:

As representações do mundo social assim construídas, embora aspirem à universalidade de um diagnóstico fundado na razão, são sempre determinadas pelos interesses de grupo que as forjam. Daí, para cada caso, o necessário

${ }^{5}$ CHARTIER, Roger. A história cultural entre práticas e representações. Rio de Janeiro: Bertrand Brasil; Lisboa [Portugal]: Difel, 1990. P. 17.

Revista Vernáculo n. ${ }^{\circ} 41$ - primeiro semestre $/ 2018$

ISSN 2317-4021 
relacionamento dos discursos proferidos com a posição de quem os utiliza. ${ }^{6}$

No caso do Movimento Udleinista, é possível analisar os processos de construção de representações sobre o passado, tanto em discursos de apoio ao movimento, ou em discursos de repressão a ele. Parte desse discurso, ou um pouco de cada representação, influencia a obra literária de Adilson Vilaça. Ele é jornalista, capixaba, o pesquisador vivo que há mais tempo trabalha com essa questão. Escreveu livros de literatura, crônicas e até uma obra historiográfica. $\mathrm{O}$ seu livro de maior repercussão foi Cotaxé, um romance histórico baseado nos acontecimentos do Movimento Udelinista relatados acima. Obra que chegou a sua quinta edição em 2015, ano em que passa a ser distribuído também em Portugal. Vale ressaltar que esse é um livro que amiúde se encontra nas bibliotecas das escolas públicas do Espírito Santo, tendo um impacto significativo na cultura capixaba.

Já o seu livro de cunho historiográfico, intitulado Cotaxé: A reinvenção de Canudos, publicado em 2007 pelo Instituto Histórico e Geográfico do Espírito Santo, Vilaça representa o movimento como messiânico, e afirma que Udelino Alves de Matos era, além de um líder político, um guia religioso. Para além da questão messiânica, também é representado nesta obra que um dos seus objetivos dos posseiros era criar um novo ente federativo, o Estado União de Jeovah.

${ }^{6}$ Ibidem. P. 16

Revista Vernáculo n. ${ }^{\circ} 41$ - primeiro semestre /2018

ISSN 2317-4021 
Nesta pesquisa, a literatura é utilizada como fonte histórica, pois ela nos apresenta uma interpretação do passado e que interfere diretamente no imaginário. Quem leu as obras de Vilaça passa a construir uma memória sobre o passado em Cotaxé, mesmo que através da literatura e não por meio de fontes. Afinal

a ficção não seria [...] o avesso do real, mas uma outra forma de captá-la, onde os limites da criação e fantasia são mais amplos do que aqueles permitidos ao historiador [...]. Para o historiador a literatura continua a ser um documento ou fonte, mas o que há para ler nela é a representação que ela comporta [...] o que nela se resgata é a reapresentação do mundo que comporta a forma narrativa. ${ }^{7}$

Entendemos, então, que as obras de Vilaça são, tanto influenciadoras da memória dominante, como também, influenciada por questões sociais de sua época, que transparecem nos seus escritos. Apesar das obras terem publicações recentes, muito do que o autor utiliza para escrever seus romances, são memórias, impressões, que tinha em sua infância e adolescência em que viveu na região de Cotaxé. Seu imaginário transcende ao factual e se constrói enquanto ficção.

A literatura portanto fala ao historiador sobre a história que não ocorreu, sobre as possibilidades que não vingaram, sobre os planos que não se concretizaram. Ela é o testemunho triste, porém

${ }^{7}$ PESAVENTO, Sandra Jatahy. Relação entre História e Literatura e Representação das Identidades Urbanas no Brasil (século XIX e XX). In: Revista Anos 90, Porto Alegre, n. 4, dezembro de 1995. P. 117

Revista Vernáculo n. ${ }^{\circ} 41$ - primeiro semestre /2018

ISSN 2317-4021 
sublime, dos homens que foram vencidos pelos fatos. $^{8}$

Essa história que "não ocorreu” e que está presente nos livros de Vilaça, nos interessa, pois é essa interpretação que se constrói enquanto memória cultural sobre o passado do vilarejo. Compreender essas interpretações possibilita entender a memória da própria região. Afinal, essa memória influenciou a obra literária, além de ser influenciado por ela, também.

Ao começarmos a análise da obra literária Cotaxé, logo na nota da primeira edição, o autor deixa claro que seu livro não se trata de uma reprodução, nem mesmo uma construção de uma verdade sobre o passado: "Não é tarefa do artista contar as coisas como sucederam, mas como poderia ter sucedido"9. Porém, mesmo esclarecendo que aquela não é uma obra histórica e sim literária, de ficção, o romance ajuda a construir todo um imaginário sobre o acontecimento.

Ao analisarmos a obra de Vilaça devemos nos atentar para as representações que o autor faz de Udelino Alves de Matos, pois devemos entender "personagem como um ser fictício responsável pelo desempenho do enredo: quem realiza a ação."10 Os personagens, reais ou não, individuas e/ou coletivos, são os responsáveis pelas ações que iremos discutir ao longo desta análise. Portanto, sempre ao analisarmos

${ }^{8}$ SEVCENKO, Nicolau. Literatura como missão: tensões sociais e criação cultural na Primeira República. 2a . ed. São Paulo: Companhia das Letras, 2003. P. 30.

${ }^{9}$ VILAÇA, Adilson. Cotaxé. Vitória: Textus, $4^{\mathrm{a}}$ ed., 2007. P. 13

${ }^{10}$ MOTTA, Luiz Gonzaga. Análise Crítica da Narrativa. Brasília: Editora UnB, 2013. P. 173.

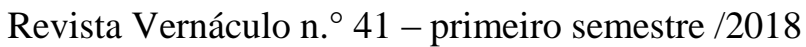

ISSN 2317-4021 
o movimento e o seu suposto messianismo, estamos analisando como Udelino e sua relação com os demais udelinistas são interpretadas, pois elas são necessárias para a compreensão das representações do próprio movimento.

O romance Cotaxé, além de retratar o movimento como uma tentativa de construção do Estado de União de Jeovah, conta uma história romântica entre Udelino Alves de Matos e sua amada Isabel, porém seu amigo acaba roubando sua pretendida pedindo a mão dela em casamento antes dele. Além disso, há outros triângulos amorosos dentro do livro. João come-vivo, personagem que representa o braço direito de Udelino, o Jorge Come-cru, acaba se envolvendo com a governanta da Casa de Tábua, no romance, sede administrativa do Estado de União de Jeovah. O grande problema está no fato de ela ser casada com outro posseiro. Várias histórias pessoais dos personagens atravessam o romance, e a maioria delas acaba em desgraça. Na obra de Vilaça, Udelino vai embora deixando sua amada casada com o seu amigo, e João Come-vivo acaba sendo morto pelos militares do Estado do Espírito Santo.

Em relação ao caráter messiânico do Movimento Udelinista, há na obra literária de Vilaça uma construção do personagem Udelino como uma pessoa extremamente religiosa, e enquanto líder político deixa a impressão de ser também um líder religioso, criando assim uma imagem de que o movimento tinha um caráter messiânico.

Revista Vernáculo n. ${ }^{\circ} 41$ - primeiro semestre /2018

ISSN 2317-4021 
É comum encontrar no romance Cotaxé que "Os ventos de Canudos ainda animavam os sertões, e Udelino, de naturalidade baiana, estava impregnado da herança de Antônio Conselheiro quando chegou ao contestado"11. Porém, não há nenhuma evidência empírica para tal afirmação. Ela surge de uma pressuposição de que o líder dos posseiros, por ser baiano, pode ter tido conhecimento e admiração dos acontecimentos de Canudos.

Mas afinal, o que diferencia um movimento político de um movimento messiânico? Inicialmente é importante compreender o conceito apresentado por Maria Isaura Queiroz, para quem o messianismo consiste em uma doutrina, podendo ser cristã ou qualquer outra forma de religiosidade. Essa doutrina obrigatoriamente gera um movimento social/religioso, em que é respeitada toda a sua lógica interna que varia conforme cada doutrina. $\mathrm{O}$ movimento messiânico necessita de um líder, no caso o messias, ou o profeta, que deve ser carismático, tendo características de um líder religioso, sendo considerado um filho de Deus, ou um enviado divino, responsável pela melhora na sociedade em que vivem seus seguidores ${ }^{12}$.

A principal diferença entre a religião tradicional e o messianismo consiste na relação da atividade efetiva dos adeptos. Enquanto a religião tradicional se fixa apenas em uma celebração divina em conformidade

${ }^{11}$ VILAÇA, Adilson. Cotaxé. Vitória: Textus, $4^{\mathrm{a}}$ ed., 2007. P.15.

${ }^{12}$ QUEIROZ, Maria Isaura Pereira de. O messianismo: no Brasil e no mundo. São Paulo: Dominus Editora / Edusp, 1965.

Revista Vernáculo n. ${ }^{\circ} 41$ - primeiro semestre $/ 2018$

ISSN 2317-4021 
com a realidade, os movimentos messiânicos lutam, não importando como, para que a justiça seja instaurada na terra:

O messianismo se afirma, pois, como uma força prática, e não como uma crença passiva e inerte de resignação e conformismo: diante do espetáculo das injustiças, o dever do homem é trabalhar para sanálas, pois sua é a responsabilidade pelas condições do mundo. $^{13}$

Percebe-se então que um movimento messiânico precisa de uma crença, somada a uma luta política, uma ação transformista, regida e incentivada pela crença em questão. Complementando a compreensão do conceito de messianismo, é relevante citar Maurício Vinhas de Queiroz, que compara um movimento messiânico a um movimento social laico:

O messianismo significa algo mais que um simples "desgosto" pelo mundo, ou uma não-aceitação da vida social como esta se revela. Nos movimentos revolucionários laicos, há também uma recusa às condições de existência, porém os revolucionários procuraram atuar dentro da realidade, a fim de transformá-la. Já o messianismo leva sempre a um alheamento, a um desligamento do corpo social, e à instauração, fora dele e oposta a ele, de uma nova comunidade que confia na transfiguração supranaturista do mundo ${ }^{14}$.

${ }^{13}$ Ibidem. P. 07.

${ }^{14}$ QUEIROZ, Mauricio Vinhas de. Messianismo e conflito social: a guerra sertaneja do Contestado: 1912-1916. Rio de Janeiro: Civilização Brasileira, 1996. P. 252/253.

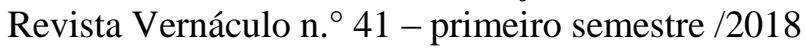

ISSN 2317-4021 
Além de uma fé, é necessária a ação dos indivíduos envolvidos, o que gera um movimento de motivação política e religiosa. Entendemos então que para considerarmos um movimento enquanto messiânico, a luta política caminha lado a lado de uma fé religiosa, uma crença espiritual no líder, no qual, por ser um enviado de Deus, teria o poder da verdade e a capacidade de liderança. Porém, "o apelo a valores religiosos não seria uma atitude alienada, mas a expressão da revolta por meio do único canal possível no contexto cultural tradicional"15.

Conceituar é sempre uma tarefa complicada, pois podemos cometer erros generalistas e deixar de lado especificidades de cada movimento. Porém, conceituar um movimento enquanto messiânico, ou não, faz parte de um processo taxonômico que auxilia na compreensão inicial de tais acontecimentos.

Como conceitos abrangentes e genéricos, messianismo e movimento messiânico são necessariamente típico-ideais, no sentido de se referirem à realidade observável, mas não a reproduzirem ou esgotarem, e isto mesmo no caso em que os autores entendam seus conceitos como tipos empíricos. ${ }^{16}$

Os conceitos, portanto, não esgotam sua definição. Todos os movimentos messiânicos apresentam diferenças estruturais, culturais, contextuais. Porém, devemos nos ater a um grande ponto em comum em todos os movimentos messiânicos e todas as conceituações: tratam-

${ }^{15}$ NEGRÃO, Lísias Nogueira. Revisitando o messianismo no Brasil e profetizando seu futuro. In.: Revista Brasileira de Ciências Sociais - Vol. 16 n 46, 2001. P.122. ${ }^{16}$ Ibidem. P. 119.

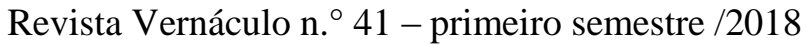

ISSN 2317-4021 
se de articulações político-religiosas. Sendo assim, o que motiva os participantes a aderirem à causa é o conjunto de objetivos de ordem secular e sagrada, entrelaçados.

Há no romance Cotaxé inúmeras cenas em que Udelino evoca o nome de Deus, faz rezas e outras atividades religiosas, como: "Udelino pregava que o território era réplica do paraíso" ${ }^{\text {17 }}$, ou uma fala do personagem no livro que dizia: "Meus colegas lavradores, amados filhos de Deus. O bom Pai nos agraciou com a oferta do paraíso"18. Nessas frases, como em tantas outras espalhadas pelo livro, é possível notar explicitamente que Vilaça representa o líder dos posseiros como um profeta, alguém que evoca Deus em seus discursos políticos.

Outro ponto que necessita de uma análise no romance Cotaxé é a passagem que relata diálogos de Udelino Alves de Matos com o personagem Francisco Rosa, membro do Partido Comunista do Brasil. A passagem mostra um diálogo entre os dois personagens sobre os conflitos agrários da região.

Após o comício, um representante dos comunistas esperava Udelino detrás do coreto. Era um rapaz claro, de olhos castanho-esverdeados, chamado Francisco Rosa.

- Acho que é um homem inteligente e não vai iniciar uma guerra. Os camponeses não estão preparados para essa tarefa. Falta organização.

- Quem é você? - quis saber Udelino.

- Francisco Rosa. Pode me chamar de Chico.

- Então o senhor que é o tal Chico, o ateu?

${ }^{17}$ VILAÇA, Adilson. Cotaxé. Vitória: Textus, $4^{\mathrm{a}}$ ed., 2007. P. 15.

${ }^{18}$ Ibidem, p. 63.

Revista Vernáculo n. ${ }^{\circ} 41$ - primeiro semestre /2018

ISSN 2317-4021 
- Se o senhor prefere assim, assim pode ser. O que o senhor não pode fazer é misturar a questão agrária com essa ridícula ideia de fazer um novo estado. Por que não repensamos a estratégia? Podemos nos aliar. - Ridículos são os senhores, que não passam e meia dúzia que não tem nem o respeito do povo - foi a resposta de Udelino. E mais: - O povo está comigo, e Deus nos protegerá!

- O senhor é um populista! - Reagiu Chico Rosa.

- E o senhor já está cheirando a defunto!

Imune à ameaça, Chico Rosa voltou-se as costas e foi ajuntar-se a outros três, quatro membros do Partido, que o esperavam do outro lado da praça.

- O sujeito é megalomaníaco! - Sintetizou aos camaradas. ${ }^{19}$

Nessa cena percebemos que há uma representação do Partido Comunista do Brasil na figura de Francisco Rosa, como o sábio, que percebia que o Movimento Udelinista não daria certo, criticando seu líder, chamando-o de "populista" e "megalomaníaco". E Udelino, sempre baseado em Deus, seria um fanático religioso que colocava o movimento agrário em grande perigo. Nesta cena, percebemos que as falas sobre Deus criam a imagem de um extremista religioso, e a maior crítica ao personagem Rosa é o fato de ser ateu. Há então uma nítida divisão entre os personagens: Udelino sendo um fanático religioso, um inconsequente; enquanto Francisco Rosa seria uma pessoa racional, que conseguiria levar o movimento agrário de forma mais sábia. Sendo assim, o Movimento Udelinista, ou como o autor denomina, o "Estado União de Jeovah" seria um movimento desarticulado, sem força, e o

${ }^{19}$ Ibidem. P. 197/198.

Revista Vernáculo n. ${ }^{\circ} 41$ - primeiro semestre /2018

ISSN 2317-4021 
$\mathrm{PCB}^{20}$ com a capacidade de fazer um movimento muito mais articulado, racional e com força política.

A interpretação apresentada no romance histórico acabou sendo dominante, afinal é a obra mais conhecida sobre Cotaxé. Ela atinge, inclusive, materiais didáticos. Podemos comparar a importância da obra Os Sertões de Euclides da Cunha ao se trabalhar com Canudos, à importância de Cotaxé de Adilson Vilaça para trabalharmos com o Movimento Udelinista. Porém, obviamente, devemos entender as diferenças proporcionais das repercussões literárias, afinal, Canudos acaba sendo conhecido no âmbito nacional, enquanto Cotaxé em âmbito local.

Tamanha é a importância do livro para a história do Espírito Santo que Cotaxé até ganhou uma obra de análise literária. Maria Beatriz Albaurre escreveu A metaficcção histórica no romance "Cotaxé" de Adilson Vilaça, publicado pelo Instituto Histórico e Geográfico do Espírito Santo. A autora faz sua análise levando em considerações alguns aspectos linguísticos utilizados por Vilaça. Ela nos chama a atenção a alguns detalhes da obra como:

Udelino, por exemplo, em meados da trama, começa a ter uma linguagem contida, repetida três vezes, como uma oração, enfatizando o que fala. [...]. Percebe-se também, podendo-se fazer uma analogia, a simbologia da repetição que pode ser vista como

${ }^{20}$ PCB era a sigla do Partido Comunista do Brasil até o ano de 1962, quando houve uma cisão e o PCB passou a ser o Partido Comunista Brasileiro e o PCdoB o Partido Comunista do Brasil.

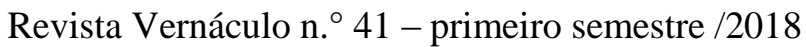

ISSN 2317-4021 
um ato místico, sendo o três um algarismo cabalístico envolto a muitos mistérios. ${ }^{21}$

Esse detalhe apresentado por Alburre serve para ilustrar como não só diretamente Vilaça representa Udelino como um personagem extremamente religioso, mas utiliza da linguagem nas falas do personagem para reforçar tal ideia. Falar de forma repetitiva, o que Alburre interpreta "como uma oração", reforça essa imagem religiosa de Udelino na obra literária. Na análise em questão, a autora reconhece o caráter religioso exaltado do personagem e entende o movimento enquanto messiânico.

Em 2010 saiu uma reportagem em um jornal de grande circulação no Espírito Santo, A Tribuna, em que é possível constatar tal interpretação de Udelino: "Magro, alto e sempre usando terno preto, Udelino, que não gostava de fotografias, recorria à Bíblia para unir os camponeses."22. Percebemos nesta reportagem, uma representação até caricata de um líder religioso. O mesmo ocorreu em uma reportagem de 1997, no jornal A Gazeta, também de grande circulação no Espírito Santo, onde, em uma entrevista com Adilson Vilaça, reforçam a ideia de que "este estado [União de Jeovah] seria baseado em uma religiosidade muito forte. Ele prometia um paraíso em terra, e com esta

21 ALBURRE, Maria Beatriz Figueiredo. A metaficção histórica no romance "Cotaxé", de Adilson Vilaça. Vitória: Instituto Histórico e Geográfico do Espírito Santo, 2000. P. 95/96)

${ }^{22}$ SEGANTTINI, Fábio. Um estado diferente do Norte. A Tribuna. 25 de abril de 2010. P. 18.

Revista Vernáculo n. ${ }^{\circ} 41$ - primeiro semestre /2018

ISSN 2317-4021 
promessa encantava as pessoas. ${ }^{, 23}$ Vale frisar que a reportagem em questão foi publicada devido ao lançamento do romance histórico Cotaxé, portanto já era de se esperar que apresentasse o movimento da mesma maneira.

Fato semelhante também pode ser encontrado no material paradidático de maior circulação sobre o Espírito Santo. No livro História e Geografia do Espírito Santo de Thais Moreira e Adriano Perrone, é possível encontrar mais uma vez a representação messiânica: "Foi criado pelo movimento o Estado de União de Jeová, num misto de questão fundiária e pregação religiosa" ${ }^{24}$. Por se tratar de um material didático, é provável que para sua escrita foram pesquisados materiais de referência sobre o tema, sendo Adilson Vilaça reconhecido como o maior pesquisador desta temática, perpetuando sua interpretação. Neste caso é mantido tanto o messianismo, quanto o objetivo de criar um novo estado na região, o Estado União de Jeovah..

No ano 1999 Adilson Vilaça deu consultoria a um documentário sobre o tema, dirigido por Joel Zito Araújo, intitulado Cotaxé: $O$ efêmero Estado de União de Jeovah. No filme encontram-se entrevistas feitas por Vilaça na vila; cenas que representam como seria Udelino Alves de Matos e o conflito na região; além de trechos explicativos sobre o movimento, narrado pelo próprio jornalista.

${ }^{23}$ CURRY, Andréia. Udelino prometia um paraíso na terra. A Gazeta. 10 de agosto de 1997. P. 3.

${ }^{24}$ MOREIRA, Thaís Helena L.; PERRONE, Adriano. História e Geografia do Espírito Santo. Vitória: [s.n.], 2007. P. 126.

Revista Vernáculo n. ${ }^{\circ} 41$ - primeiro semestre $/ 2018$

ISSN 2317-4021 
Em seu livro Cotaxé: a reinvenção de Canudos, Vilaça afirma que "é nesse documentário que se evidencia a negação da origem messiânica do movimento jeovense ${ }^{25}$, por mim perpetrada contra todas as evidências que mesmo lá, na edição veiculada, se estampam"26. Adilson Vilaça reconhece que suas interpretações sobre o movimento podem ter falhas e precisam ser revistas. Apesar de, com um olhar mais atento, ser possível perceber no documentário uma reprodução desse caráter messiânico. O produto final, enquanto filme documentário, material audiovisual, reforça todo o estereótipo de um Udelino profeta e de um movimento sociorreligioso.

Vilaça, ainda em seu livro Cotaxé: a reinvenção de Canudos, lançado em 2007, questiona o messianismo da organização dos posseiros. O livro propõe ser uma pesquisa histórica, realizada durante um curso de pós-graduação lato sensu em História pela Universidade Federal do Espírito Santo (UFES). A monografia foi publicada em formato de livro pelo Instituto Histórico e Geográfico do Espírito Santo (IHGES).

Logo na introdução Vilaça apresenta os objetivos daquela pesquisa, afirmando que "a questão fundamental que orienta [...] esta investigação é aquela que interroga qual o parentesco messiânico que vincula a fundação de Canudos e a criação do Estado de União de

\footnotetext{
${ }^{25}$ Termo utilizado por Adilson Vilaça para definir o Movimento Udelinista. Jeovense remete ao Estado União de Jeovah, que na tese de Vilaça, foi criado pelos posseiros de Cotaxé.

26 VILAÇA, Adilson. Cotaxé: a reinvenção de Canudos. Vitória: IHGES, 2007. P. 09.
}

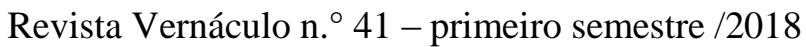

ISSN 2317-4021 
Jeovah"27. A obra, portanto, procura questionar as representações feitas anteriormente sobre os dois movimentos. Tal ideia fica ainda mais evidente quando o autor reconhece que pode ter cometido alguns erros em suas interpretações anteriores, como em seu romance histórico.

Neste caso, em essência dar-se-á à produção do autor a oportunidade de corrigir a trajetória de sua investigação, uma concessão que, no entanto, exige melhor apuração teórica para o desenvolvimento e a consubstanciação de um novo modelo interpretativo entre os dois movimentos sociais focalizados. ${ }^{28}$

Há então, logo na introdução, questionamentos sobre o caráter messiânico do Movimento Udelinista. Porém o autor não o desconstrói ao longo da sua obra. É possível encontrar diversas passagens em que o messianismo é reforçado. Como na passagem:

Em meio à tanta desagregação, Udelino não tardou em descobrir que havia uma língua para unificar os deserdados: o dialeto da terra, de mãos dadas com uma religiosidade que fundia Deus ao metafísico coletivo. Logo posseiros capixabas e mineiros uniram-se aos da Bahia para ouvir-lhe a pregação messiânica. ${ }^{29}$

Luta política "de mãos dadas com uma religiosidade" é uma descrição clara de um movimento messiânico. Principalmente quando Vilaça diz que o discurso político e religioso de Udelino foi o unificador do grupo de posseiros. Em diversas outras passagens ao

\footnotetext{
${ }^{27}$ Ibidem. P. 10.

${ }^{28}$ Ibidem. P. 11.

${ }^{29}$ Ibidem. P. 18.
}

Revista Vernáculo n. ${ }^{\circ} 41$ - primeiro semestre /2018 
longo da obra tais características são reforçadas. O próprio termo "líder messiânico" é utilizado em passagens seguintes para referir a Udelino. Ao descrever o fim do movimento Vilaça afirma: "Mas o sonho messiânico não sobreviveria ao poder repressor advindo da organização política do Estado"30. Há então um reconhecimento explícito do movimento enquanto messiânico.

A grande crítica que o livro faz sobre as interpretações anteriores é em relação ao desmerecimento político do movimento pelo fato de ser messiânico. Segundo Vilaça o grande problema existe porque "no Brasil, tantas e tantas vezes, o messianismo conduziu a sublevação no campo que, por erro de foco, seria delimitada ora como surto de fanáticos, ora rebelião alucinatória de despossuídos”31. Em toda a sua obra, o autor nos mostra que, mesmo tendo um caráter messiânico, o Movimento Udelinista teve uma consciência política louvável, sendo um movimento social legítimo e não um simples um surto generalizado.

Esses reducionismos históricos atingem boa parte dos movimentos sociais do campo. É fácil encontrar escritos sobre Canudos que representam Antonio Conselheiro como um louco e/ou fanático religioso. Flávio Costa afirma

não ser raro que algumas personagens históricas passem à História como heróis, sábios, loucos ou santos por uma força desta tendência redutora, compactadora, que em muitas ocasiões leva historiadores e escritores a pintarem amplos retratos

${ }^{30}$ Ibidem. P. 121.

${ }^{31}$ Ibidem. P. 85.

Revista Vernáculo n. ${ }^{\circ} 41$ - primeiro semestre /2018

ISSN 2317-4021 
psicológicos de certas personagens símbolo, a partir de poucos detalhes, de uma certa particular situação a que o ser ou sua vida estão associados, às vezes de forma passageira ou por circunstâncias esporádicas. $^{32}$

Ao pesquisar esses movimentos, devemos tomar cuidados com essas visões redutoras que acabam gerando mais estereótipos, dificultando a compreensão da complexidade que envolve o Movimento Udelinista. Para além dessa discussão, é necessário compreender a cultura local do sertanejo para entender sua forma de luta social. Em sua maioria são culturas muito ligadas à religião, principalmente ao catolicismo, e muitas vezes repletos de sincretismos. Essa religiosidade acaba interferindo no modo de ver e pensar os movimentos sociais.

Portanto, está coerente a argumentação de Vilaça em relação a complexidade de pesquisar Cotaxé. Devemos dar destaque as suas afirmações em relação aos trabalhos que buscam representar movimentos sociais do campo, como Canudos e o Movimento Udelinista, ora como simplesmente um movimento político, ora como simplesmente um fanatismo religioso:

Reduzir a perspectiva do movimento social de Canudos apenas a fanatismo ou restringir o contorno do movimento jeovense apenas à solicitação da demanda secularmente reprimida de uma reforma agrária é manobra que parcializa e, consequentemente, deturpa a verdadeira dimensão configuradora de tais movimentos - a combinação

${ }^{32}$ COSTA, Flávio José Simões. Antonio Conselheiro, louco? Ilhéus, Editus, 1998. P. 119.

Revista Vernáculo n. ${ }^{\circ} 41$ - primeiro semestre /2018

ISSN 2317-4021 
de predição de um mundo melhor e seu alcance, sua construção. ${ }^{33}$

Compreendo que o caráter religioso dos movimentos deve ser entendido e analisado, porém seria necessário encontrar fontes que comprovem que o movimento teria sido messiânico, pois ao tratarmos de uma pesquisa histórica precisamos de alguma empiria, o que não é apresentado de forma clara em sua obra.

Apesar de questionar alguns aspectos das obras citadas acima, reconheço a importância delas para a historiografia de Cotaxé. Obras respeitáveis, preocupadas com a preservação da memória dos movimentos agrários do noroeste do Espírito Santo. São trabalhos com diferentes objetivos finais, mas que valorizam a história e a cultura local de um espaço visto como periférico na História do Espírito Santo e na História de Minas Gerais.

A grande dúvida que surge ao analisar tais obras é: como surgiu essa representação messiânica? E por quem foi criada? Em busca de compreender seu processo de construção foram encontrados alguns documentos. Entre eles uma Comissão Parlamentar de Inquérito, aberta para apurar excessos da Polícia Militar do Espírito Santo, na região de Cotaxé. No processo constam os relatórios do major Djalma Borges, líder do grupo militar responsável pela repressão do Movimento Udelinista, pode se encontrar explicitamente a representação de que os posseiros objetivavam criar um novo estado. Como pode-se notar

${ }^{33}$ VILAÇA, Adilson. Cotaxé: a reinvenção de Canudos. Vitória: IHGES, 2007. P. 81.

Revista Vernáculo n. ${ }^{\circ} 41$ - primeiro semestre /2018

ISSN 2317-4021 
também em seu depoimento na Comissão Parlamentar de Inquérito aberta em 1953:

Ao amanhecer da segunda noite, às seis horas da manhã de 28 de fevereiro de 1953, deparou a diligência com o lugar denominado Corrego Capela d'Ema, onde se achava localizada a sede do governo provisório do Estado "União de Jeová"; que o referido "Estado" se compunha de terras dos municípios de Conceição da Barra, São Mateus, Barra de São Francisco, Ametista e Joeirana no Estado do E. Santo, e Teófilo Otoni e Carlos Chagas no Estado de Minas Gerais; que o símbolo do Estado era uma bandeira verde com uma faixa branca e dizia Udelino, mostrando um livro com sêlos, que o "ESTADO" fora criado por ordem do Presidente da República a conselho do deputado federal Wilson Cunha, e que aquele livro era o seu decreto de nomeação de administrador federal do "Estado União de Jeová. ${ }^{34}$

Para Djalma Borges, o Estado de União de Jeovah era um estado organizado, com sede administrativa, bandeira e cargos funcionais. Vale ressaltar que ele menciona a ajuda do deputado federal Wilson Cunha nesse processo. É importante termos em mente que essa CPI somente foi aberta na Assembleia Legislativa do Espírito Santo, graças a constantes denúncias feitas por Cunha a respeito dos abusos de poder e excessos de violência cometidos pela Polícia Militar do Espírito Santo na região contestada, sendo Borges o responsável por esse grupo de militares.

${ }^{34}$ ESPÍRITO SANTO (estado). Assembleia Legislativa. Comissão Parlamentar de Inquérito, $\mathbf{n}^{\mathbf{0}}$ 71/53. 16 de abril de 1953. P. 109.

Revista Vernáculo n. ${ }^{\circ} 41$ - primeiro semestre $/ 2018$

ISSN 2317-4021 
A bandeira citada por Borges, verde com uma faixa branca na diagonal, é utilizada até hoje na região, em uma festa religiosa denominada "roubo da bandeira". "A tradição ocorria nos dias joaninos, de 13 de junho, dia de Santo Antonio, a 29 de junho, dia de São Pedro." ${ }^{35}$ Devido ao seu uso religioso é comum, até os dias de hoje, vêla hasteada em algumas localidades próximas a Cotaxé. Ainda de acordo com Vilaça, "a bandeira simbolizava a floresta e a marcha do lavrador na colonização da terra." ${ }^{\text {36 }}$. Borges associa o rito religioso ao movimento agrário, afirmando que ela seria símbolo do Estado União de Jeovah. Porém, além dos relatos do Djalma Borges, não foi encontrada nenhuma outra fonte que reafirme a sua utilização pelo Movimento Udelinista. Eles habitavam o mesmo tempo e o mesmo espaço, porém a bandeira está relacionada e um rito religioso, não relacionado diretamente ao movimento político agrário.

Outro documento encontrado que compara o movimento a Canudos é um ofício de Jones dos Santos Neves, então governador do Espírito Santo, endereçado ao Ministro de Justiça e Negócios Interiores, do Governo Federal. O ofício tornou-se necessário pois, após denúncias a respeito da ação da Polícia Militar do Espírito Santo na região de Cotaxé, o Governo Federal questionou a ação policial devido ao excesso de violência por eles praticados. O ofício, portanto, trata-se de uma resposta do governo capixaba justificando a necessidade de se acabar com o Movimento Udelinista:

${ }^{35}$ VILAÇA, Adilson. Cotaxé. Vitória: Textus, $4^{\text {a }}$ ed., 2007. P. 109.

${ }^{36}$ Ibidem. P. 113.

Revista Vernáculo n. ${ }^{\circ} 41$ - primeiro semestre /2018

ISSN 2317-4021 
O brioso oficial major Djalma Borges, é um testemunho eloquente da grave anormalidade reinante na região que, não fossem as prontas $\mathrm{e}$ enérgicas providências repressivas adotadas pela Polícia do nosso Estado, bem se poderia transformar em um novo Canudos, eis que, para tal, até a exploração mística da ingenuidade da nossa massa rural se fazia presente, nos propósitos de um aventureiro que ali criara a "República União de Jeovah"! 37

Para justificar tal repressão violenta, o governo capixaba se apropria do discurso do Major Djalma Borges, afirmando que o Movimento Udelinista pretendia criar um "novo Canudos", e que Udelino explorava a "ingenuidade da nossa massa rural". Apresenta-se nesse discurso uma representação pejorativa, tanto de Canudos, quanto do Movimento Udelinista. Não só os representa como messiânico, mas também caracteriza os líderes, tanto Antonio Conselheiro, como Udelino Alves de Matos, como aproveitadores da população rural.

Porém, na imprensa espiritossantense havia um jornal comunista, intitulado Folha Capixaba. Esse jornal, por sua vez, defendia declaradamente os movimentos agrícolas na região de Cotaxé, por estarem dentro de um ideal de reforma agrária, uma das bandeiras do Partido Comunista do Brasil (PCB). Em 1955, dois anos após a repressão feita ao Movimento Udelinista, o Folha Capixaba faz uma matéria especial sobre a situação agrária na região norte e noroeste do Espírito Santo. Vale ressaltar que nesse período, o PCB já havia

${ }^{37}$ ESPÍRITO SANTO (estado). [Ofício] N. G. 1417. Vitória, 09 de abril de 1953. [para] Ministério da Justiça e Negócios Interiores. Rio de Janeiro.

Revista Vernáculo n. ${ }^{\circ} 41$ - primeiro semestre $/ 2018$

ISSN 2317-4021 
enviado militantes a região para coordenar os movimentos dos posseiros, articulando-os com as demais militâncias comunistas nacionais. Nessa reportagem é feito um histórico do movimento na região, em que o Movimento Udelinista é citado.

Os membros da Comissão de Inquérito comparam o episódio a Canudos, numa tentativa de confundir os fatos e mistificar a opinião pública. Em verdade, o que os posseiros, dirigidos por Udelino de Matos, fizeram foi defender as suas posses e resistir às violências incríveis da polícia que, no caso, agiu com uma bestialidade. ${ }^{38}$

No Folha Capixaba, a representação do movimento é feita de forma contrária à frequentemente encontrada nas demais mídias e nos documentos oficiais. O jornal, inclusive, cita a imagem messiânica construída, comparando-o a Canudos, como forma de negar a existência de tal caráter. Trata-se de um jornal que apoiou os posseiros no seu período de luta, e que, em um momento futuro, faz uma reportagem, relembrando o Movimento Udelinista e defendendo-o perante o que era divulgado nas demais mídias. .

Outra fonte de fundamental importância nesta pesquisa é a memória dos moradores da vila de Cotaxé, que se diferencia da história tradicional do Movimento Udelinista. Ao trabalharmos com memória, devemos levar em consideração o trabalho de João Camilo Penna, ele utilizou em suas pesquisas a memória de Rigoberta Menchú, uma

${ }^{38}$ SANGRENTA e cheia de crimes a história do monopólio de terras no Espírito Santo. Folha Capixaba, ed. 962. Vitória: sábado, 21 de maio de 1955. P. 04.

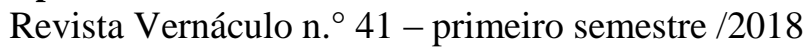


indígena que representava a identidade de seu povo de forma diferente da existente na história dita tradicional. $\mathrm{O}$ autor defende que "a importância do testemunho na América Latina espanhola está ligada à possibilidade de dar expressão a culturas com uma inserção precária no universo escrito e uma existência quase que exclusivamente oral"39. Apesar de ser possível encontrar fontes que falam em favor do Movimento Udelinista, elas são escassas, sendo importante buscar as fontes orais como forma de obtermos mais informações sobre o movimento, com a ótica dos próprios moradores da vila. Torna-se importante reconhecer a memória produzida na vila que não foi registrada de forma documental escrita.

Pensando nas diferentes memórias criadas sobre o movimento, utilizamos os conceitos de "memória cultural" e "memória comunicativa" apresentados por Assmann:

Há, então, um paralelo entre a memória cultural, que supera épocas e é guardada em textos normativos, e a memória comunicativa, que normalmente liga três gerações consecutivas e se baseia nas lembranças legadas oralmente. ${ }^{40}$

Há portanto, na história do movimento agrário de Cotaxé, uma memória cultural criada, a partir dos documentos escritos e da literatura, que se constrói de forma diferente da memória comunicativa, ou seja,

${ }^{39}$ PENNA, João Camillo. Este corpo, esta dor, esta fome: Notas sobre o testemunho hispano-americano. In: SELIGMANN-SILVA, Márcio. (org.). História, memória, literatura: O testemunho na era das catástrofes. Campinas: Ed. Unicamp, 2003. P. 305.

${ }^{40}$ Assmann (2011, p. 17)

Revista Vernáculo n. ${ }^{\circ} 41$ - primeiro semestre /2018

ISSN 2317-4021 
da memória dos próprios moradores da região. Os conflitos de representação encontrados nas memórias são percebidos pelo conflito de uma memória cultural, já estabelecida, em detrimento de uma memória comunicativa, com menos poder de visibilidade.

Porém, ao analisar as memórias, é necessário cautela, pois "lembrar não é reviver, mas refazer, reconstruir, repensar, com imagens e ideias de hoje, as experiências do passado." (BOSI 1994, p. 65) Portanto, as memórias trazem impressões do presente sobre o passado, podendo distorcê-lo. Porém, essas alterações não inviabilizam a utilização dessas memórias orais.

Os relatos testemunhais são "discurso" nesse sentido, porque têm como condição um narrador implicado nos fatos, que não persegue uma verdade externa no momento em que ela é enunciada. [...] E, como observava Halbwachs, o passado se distorce para introduzir-se coerência. (SARLO, 2007, p. 49)

Em busca dessas coerências do presente sobre o passado, na ótica dos pequenos agricultores da região, foram realizadas entrevistas em 2010, nas quais foi possível encontrar memórias bastante distintas da representação apresentada pelas obras escritas. Um dos entrevistados foi o senhor Josué Brochini Serra, também conhecido como o "Amor do Cotaxé", foi posseiro, filho de um udelinista, que se mudou para Cotaxé em 1952 quando tinha 7 anos de idade.

E: Você saberia me dizer o que levou as pessoas a apoiarem Udelino?

Revista Vernáculo n. ${ }^{\circ} 41$ - primeiro semestre /2018

ISSN 2317-4021 
J: [...] Udelino chegou aqui numa época que o povo não tem um líder, todo mundo iria com a cabeça que queria. Udelino chegou e botou na cabeça do povo que se criasse um estado aqui [...] poderia vir coisas melhores [...]. Um estado onde o povo tinha mais direitos, onde o povo tinha mais união, eu acho que foi mais ou menos isso. Udelino foi um cara muito inteligente assim na maneira de liderar o povo.

E: Existia alguma ligação com religião?

J: Pelo o que eu vejo, Udelino era católico. Pelo o que eu sinto da religião da época, ele era católico. ${ }^{41}$

Nesta entrevista percebe-se que a memória do entrevistado não dá importância para a religião do Udelino, de forma que o fator religioso não foi nela incluído como relevante para o Movimento Udelinista. Havia ali uma liderança retificada pela inteligência do indivíduo. É provável que por ele conhecer as letras, e alfabetizar os demais, a comunidade acabou criando essa imagem de um Udelino inteligente.

Outro entrevistado relata a mesma situação, negando envolvimento religioso no movimento liderado por Udelino. O senhor Anísio Ribeiro de Araújo, nascido em Vitória da Conquista em 1923, e mudou-se para a região contestada em 1948. Essa entrevista também foi realizada em 2010, na mesma visita técnica da entrevista citada anteriormente.

Entrevistador: O senhor sabe qual era a religião de Udelino?

Anísio: Não sei... era católico.

$[\ldots]$

${ }^{41}$ SERRA, Josué Brochini. Estado de União de Jeovah. 2010. Entrevista concedida a Victor Augusto Lage Pena, Ecoporanga, 13 jun. 2010.

Revista Vernáculo n. ${ }^{\circ} 41$ - primeiro semestre /2018

ISSN 2317-4021 
E: O Udelino falava de religião?

A: Comigo ele nunca falou de religião.

E: O que o senhor conversava com o Udelino?

A: Sobre posseiro, sobre posse, sobre pobre. Sobre essa guerra que tinha entre fazendeiro e posseiros. A nossa conversa era essa. ${ }^{42}$

É notável que nas duas entrevistas, os entrevistados enxergam o Movimento Udelinista como um movimento agrário, sem vínculo religioso. Porém, devemos compreender que estamos falando de uma comunidade sertaneja, do interior do Espírito Santo, onde a relação com a religiosidade é intensa. Até hoje, indo à comunidade, percebe-se o seu vínculo com o cristianismo, principalmente na doutrina católica. Portanto, é muito provável que a maior parte dos udelinistas, talvez todos, tenham sido católicos. É possível também que Udelino possa ter falado de Deus nos seus discursos em alguns momentos, porém, não são suficientes para afirmar que o apelo religioso foi o motivo pelo qual os posseiros se envolveram no movimento. Logo, dificulta a afirmação de que o Udelino seria um líder também religioso, e que Movimento Udelinista seria messiânico.

É preciso reconhecer que é plenamente possível que esse discurso do passado tenha sofrido alterações com o passar dos anos, que as experiências do presente tenham modificado tal memória do passado. $\mathrm{O}$ que pode ter ocorrido por uma questão de o objetivo do movimento ser majoritariamente a distribuição de terras, o fato religioso teria sido

42 ARAÚJO, Anísio Ribeiro de. Estado de União de Jeovah. 2010. Entrevista concedida a Victor Augusto Lage Pena, Ecoporanga, 13 jun. 2010.

Revista Vernáculo n. ${ }^{\circ} 41$ - primeiro semestre $/ 2018$

ISSN 2317-4021 
omitido pelos entrevistados, ou por não ter tido tanta importância, ficou esquecido na memória. O movimento passaria a se representar com objetivos políticos. Já em relação a escolha de um líder, nota-se que Udelino se demonstra um líder carismático, conseguindo unir os posseiros da região.

O líder carismático ganha e mantém a autoridade exclusivamente provando sua força na vida. Se quer ser profeta, deve realizar milagres; se quer ser senhor da guerra, deve realizar feitos heroicos. Acima de tudo, porém, sua missão divina deve ser "provada", fazendo com que todos os que se entregam fielmente a êle se saiam bem. ${ }^{43}$

Udelino não realizava milagres na região, ao menos não há nenhum relato de milagres realizados por ele, mas ganha a confiança dos posseiros com base na sua inteligência, provando que seria o mais indicado a coordenar as ações do grupo. Ser alfabetizado e estar disposto a ensinar os analfabetos da região a ler e escrever foi uma grande ação de conquista dos posseiros. Além de inteligente, se mostrava prestativo e disposto a ajudar os demais. Assim, de forma carismática, ele passa a liderar o Movimento Udelinista.

Após analises desses documentos, escritos e orais, podemos defender a tese de que a representação messiânica do Movimento Udelinista foi criada pelo governo estadual do Espírito Santo, com o intuito de justificar as suas ações repressivas, aproveitando-se das características simples e da religiosidade de seus participantes.

${ }^{43}$ WEBER, Max. Ensaios de sociologia. Rio de Janeiro: Zahar Editores, 1963. P. 287. Revista Vernáculo n. ${ }^{\circ} 41$ - primeiro semestre $/ 2018$ 
Objetivava-se com essa representação desmerecer os objetivos do movimento, e taxar Udelino como um aproveitador. Essa representação, criada pelo governo capixaba, acabou sendo, em parte perpetuada na literatura, como vimos nos escritos de Adilson Vilaça, tornando-se a representação dominante. Nota-se que, nas fontes em que era possível ouvir os posseiros, ou quem os apoiava, não aparece nenhum caráter religioso, tornando-se impossível sustentar a tese de que era um movimento messiânico, assim como parte da bibliografia afirma.

Concluímos, por ora, que o Movimento Udelinista consistia em um movimento agrário, apartidário, com uma auto-organização dos próprios posseiros, liderados por Udelino Alves de Matos. Porém, a cultura escrita sobressai à cultura oral. A representação criada pelos documentos oficiais foi perpetuada por obras escritas, sejam literárias ou historiográficas, principalmente nas obras de Adilson Vilaça. É notável neste estudo de caso como o poder da escrita é fundamental nas lutas de representação. E o que sobreviveu ao longo do tempo, com maior vigor, foi a representação messiânica do Movimento Udelinista.

\section{Referências}

ALBURRE, Maria Beatriz Figueiredo. A metaficção histórica no romance "Cotaxé", de Adilson Vilaça. Vitória: Instituto Histórico e Geográfico do Espírito Santo, 2000. P. 95/96)

ARAÚJO, Anísio Ribeiro de. Estado de União de Jeovah. 2010. Entrevista concedida a Victor Augusto Lage Pena, Ecoporanga, 13 jun. 2010.

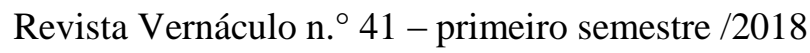

ISSN 2317-4021 
CHARTIER, Roger. A história cultural entre práticas e representações. Rio de Janeiro: Bertrand Brasil; Lisboa [Portugal]: Difel, 1990.

COSTA, Flávio José Simões. Antonio Conselheiro, louco? Ilhéus, Editus, 1998. P. 119.

CURRY, Andréia. Udelino prometia um paraíso na terra. A Gazeta. 10 de agosto de 1997. P. 3.

ESPÍRITO SANTO (estado). [Ofício] N. G. 1417. Vitória, 09 de abril de 1953. [para] Ministério da Justiça e Negócios Interiores. Rio de Janeiro.

ESPÍRITO SANTO (estado). Assembleia Legislativa. Comissão Parlamentar de Inquérito, ${ }^{\mathbf{0}}$ 71/53. 16 de abril de 1953. P. 109.

MORAES, Cícero. As questões de limites que o Espírito Santo sustentou. Vitória: Real Gráfica, 1971.

MOREIRA, Thaís Helena L.; PERRONE, Adriano. História e Geografia do Espírito Santo. Vitória: [s.n.], 2007. P. 126.

MOTTA, Luiz Gonzaga. Análise Crítica da Narrativa. Brasília: Editora UnB, 2013. P. 173.

NEGRÃO, Lísias Nogueira. Revisitando o messianismo no Brasil e profetizando seu futuro. In.: Revista Brasileira de Ciências Sociais - Vol. 16 $n^{\circ} 46,2001$. P.122.

PENNA, João Camillo. Este corpo, esta dor, esta fome: Notas sobre o testemunho hispano-americano. In:

PESAVENTO, Sandra Jatahy. Relação entre História e Literatura e Representação das Identidades Urbanas no Brasil (século XIX e XX). In: Revista Anos 90, Porto Alegre, n. 4, dezembro de 1995. P. 117

QUEIROZ, Maria Isaura Pereira de. O messianismo: no Brasil e no mundo. São Paulo: Dominus Editora / Edusp, 1965.

Revista Vernáculo n. ${ }^{\circ} 41$ - primeiro semestre $/ 2018$

ISSN 2317-4021 
QUEIROZ, Mauricio Vinhas de. Messianismo e conflito social: a guerra sertaneja do Contestado: 1912-1916. Rio de Janeiro: Civilização Brasileira, 1996. P. 252/253.

RIBEIRO, Vanderlei Vazelesk. Cartas ao Presidente Vargas: outra forma de luta pela terra. In.: MOTTA, Márcia; ZARTH, Paulo (orgs.) Formas de resistência camponesa: visibilidade e diversidade de conflitos ao longo da história, vol. I: concepções de justiça e resistência nos Brasis. São Paulo: Editora UNESP; Brasília: Ministério do Desenvolvimento Agrário, NEAD, 2008 .

SANGRENTA e cheia de crimes a história do monopólio de terras no Espírito Santo. Folha Capixaba, ed. 962. Vitória: sábado, 21 de maio de 1955. P. 04.

SELIGMANN-SILVA, Márcio. (org.). História, memória, literatura: O testemunho na era das catástrofes. Campinas: Ed. Unicamp, 2003. P. 305.

SERRA, Josué Brochini. Estado de União de Jeovah. 2010. Entrevista concedida a Victor Augusto Lage Pena, Ecoporanga, 13 jun. 2010.

SEVCENKO, Nicolau. Literatura como missão: tensões sociais e criação cultural na Primeira República. 2a . ed. São Paulo: Companhia das Letras, 2003. P. 30.

SEGANTTINI, Fábio. Um estado diferente do Norte. A Tribuna. 25 de abril de 2010. P. 18.

VILAÇA, Adilson. Cotaxé. Vitória: Textus, 4ª ed., 2007. P. 13

VILAÇA, Adilson. Cotaxé. Vitória: Textus, 4ª ed., 2007. P.15.

VILAÇA, Adilson. Cotaxé. Vitória: Textus, $4^{\mathrm{a}}$ ed., 2007.

VILAÇA, Adilson. Cotaxé: a reinvenção de Canudos. Vitória: IHGES, 2007. P. 09.

Revista Vernáculo n. ${ }^{\circ} 41$ - primeiro semestre /2018

ISSN 2317-4021 
VILAÇA, Adilson. Cotaxé: a reinvenção de Canudos. Vitória: IHGES, 2007. P. 81.

VILAÇA, Adilson. Cotaxé. Vitória: Textus, $4^{a}$ ed., 2007. P. 109.

WEBER, Max. Ensaios de sociologia. Rio de Janeiro: Zahar Editores, 1963. P. 287.

Recebido em 31/05/2017, aceito para publicação em 22/09/2017

Revista Vernáculo n. ${ }^{\circ} 41$ - primeiro semestre $/ 2018$

ISSN 2317-4021 